Edunomika-Vol. 03, No. 01 (Febuari 2019)

\title{
ANALISIS PREDIKSI TINGKAT KEBANGKRUTAN DENGAN METODE ALTMAN Z-SCORE DAN ZMIJEWSKI PADA PT BAKRIE TELECOM TBK PERIODE 2015-2017
}

\author{
Suci Ariyani ${ }^{1}$, Djumali ${ }^{2}$, Ida Aryati $^{3}$ \\ ${ }^{123}$ Fakultas Ekonomi Manajemen Universitas Batik Surakarta \\ J1. KH Agus Salim 10, Surakarta 57147, Indonesia \\ E-mail: ariyanisuci30@gmail.com
}

\begin{abstract}
The purpose of this research is to know financial condition of Bakrie Telecom Tbk company using Altman and Zmijewski's analysis model period 2015-2017, during the period so its be able to predict financial distress happened inside the company. The data used to this research is secondary data, with population telecommunication companies go public enrolled in the Indonesia Stock Exchange (BEI) period 2015-2017. Data analysis techniques that used is Altman and Zmijewski's dicriminant analysis. The Altman's analysis model classified into three company categories, which are company that is in broken condition, grey area and not bankrupt/healthy. The Zmijewski's analysis model classified into two company categories, which are potentially bankrupt company and unpotentially bankrupt company/health. The results of the Bakrie Telecom Tbk company's financial distress analysis period of 2015-2017 used the Altman's model showed that company was not in bankrupt category/health.The results of the Zmijewski's analysis model showed in 2015 was not in bankrupt category/health category and in the year 2016-2017 was in the bankrupt category.
\end{abstract}

Keywords: Altman, Bankruptcy , Zmijewski

\section{PENDAHULUAN}

Era globalisasi saat ini membuat perkembangan teknologi mangalami perkembangan yang signifikan. Penyedia layanan telekomunikasi bersaing untuk menarik pelanggan agar menggunakan layanan yang disediakan. Saat ini semakin banyak penyedia layanan maka membuat pelanggan untuk mencari dan memilih jasa layanan yang unggul. Maka sebab itu market share bidang telekomunikasi semakin ketat, sehingga hal tersebut bias menimbulkan kesulitan keuangan jika suatu perusahaan dalam bersaing tidak mempunyai kemampuan untuk keberlangsungan perusahaan yang dijalankan (Boedi dan Tiara, 2013).

Siregar, Maihetti, dan Supriyanto (2016) menyatakan bahwa dalam sebuah perusahaan akan mengalami kendala dalam menjalankan sebuah misi. Atas kondisi khusus perusahaan kemungkinan dapat merasakan menjalani financial distress misalnya tidak mampu membayar gaji karyawan dan hutang jangka pendek lainnya. Kadim dan Sunardi (2018) berpendapat keadaan seperti hal ini berdampak kepada kemerosotan kemampuan perusahaan serta bisa mengakibatkan suatu organisasi meghadapi kepailitan. Guna memperkirakan timbulnya kesulitan keuangan oleh karena itu sebuah organisasi perlu memiliki bekal sedini mungkin demi membendung supaya perusahaan tak mengalami kebangkrutan. Diharapkan sebuah organisasi mampu mengukur keadaan organisasi 
yang tengah dijalankan supaya mendapatkan prediksi kian spesifik tentang keadaan organisasi saat sekarang maka bisa mengerti langkah kedepan yang akurat bagi membentengi serta memulihkan kelemahan yang dihadapi oleh organisadi supaya mampu bersikukuh serta berkompetisi.

Effendi (2018) menyatakan bahwa dalam menganalisis potensi kebangkrutan mempunyai berbagai macam model antara lain analisis dengan metode Altman Z-Score dan analisis dengan metode Zmijewski. Motode Altman Z-Score adalah salah satu motode yang menggunakan beberapa jenis rasio agar menciptakan alat untuk memprediksi kebangkrutan. Rasio ini memiliki karakteristik yang dapat digunakan untuk meneliti kemungkinan adanya kesulitan keuangan di masa depan.

Tambunan, Dwi atmanto dan Endang N.P (2015) berpendapat bahwa metode Altman Z-Score gampang dipakai dan bisa mendapatkan peringkat keakuratan perkiraan mencapai 95\%. Metode Altman Z-Score memakai lima perhitungan rasio keuangan sebagai berikut modal kerja terhadap total harta pada variable $\mathrm{X}_{1}$, laba ditahan terhadap total harta pada variabel $\mathrm{X}_{2}$, laba sebelum bunga dan pajak terhadap total harta pada varibel $\mathrm{X}_{3}$, nilai pasar ekuitas terhadap nilai buku dari hutang pada variabel $\mathrm{X}_{4}$, dan penjualan terhadap harta pada variabel $\mathrm{X}_{5}$.

Kemudian Zmijewski (1983) metode seperti hal berikut memakai konsep yang bertentangan dibandingkan dengan metode lainnya, adalah $\mathrm{X}_{1}$ tentang rasio rentabilitas, $\mathrm{X}_{2}$ tentang rasio solvabilitas, $\mathrm{X}_{3}$ tentang rasio likuiditas dari suatu organisasi selaku faktor terutama saat melakukan prediksi kesulitan keuangan. Paham seperti ini dapat diselaraskan pada paham likuiditas, profitabilitas, serta kekayaan perusahaan. Titik cut off yang digunakan pada motode Zmijewski yaitu 0 . Sebab hal berikut memiliki arti perusahaan dengan memiliki perhitungan X lebih besar dari atau sama dengan 0 bahwa perusahaan tersebut dapat diperkirakan akan menghadapi kebangkrutan pada masa yang akan datang (Effendi, 2018).

Berdasarkan uraian dan latar belakang di atas, menjadi pertimbangan peneliti untuk membahas lebih lanjut dan melakukan penelitian mengenai prediksi tingkat kebangkrutan pada perusahaan yang bersangkutan. Dengan melihat prediksi kebangkrutan maka perusahaan dapat dikelompokan pada kondisi sehat/tidak bangkrut, grey area maupun bangkrut. Dengan ini peneliti berpendapat bahwa layak melaksanakan penelitian dengan judul Analisis Prediksi Tingkat Kebangkrutan Dengan Metode Altman Z-Score dan Zmijewski Pada PT Bakrie Telecom Tbk Periode 2015-2017.

\section{METODE PENELITIAN}

Pada penelitian ini menggunakan jenis penelitian berdasarkan tingkat kejelasan yaitu deskriptif kuantitatif. Sugiyono (2011:29) berpendapat bahwa penelitian deskriptif yakni penelitian yang dilakukan untuk memaparkan maupun memberikan gagasan pada objek yang akan diteliti menggunakan populasi atau data sampel dengan seperti apa adanya, tanpa melaksanakan analisis serta membuahkan hasil kesimpulan yang berlangsung umum. Penilitian kuantitatif ini memiliki landasan filsafat positivisme yang berfungsi sebagai metode penelitian untuk sampel atau populasi tertentu, dalam mengumpulkan data memakai instrument penelitian, pada analisis data mempunyai sifat statistik/kuantitatif yang bertujuan untuk menguji hipotesis yang sudah ditentukan (Sugiyono, 2011:8).

Dalam penelitian yang dilakukan memakai jenis data sekunder berpaham dari data history laporan keuangan PT Bakrie Telecom Tbk yang sudah teraudit pada tahun 2015 sampai dengan 2017. Menurut Sofyan (2013: 16) data sekunder yaitu data yang dimunculkan maupun dipakai oleh organisasi atau orang lain yang bukan pengolahnya.

Metode Altman Z-Score dalam melaksanakan sebuah penelitian pada variable dan sampel yang telah dipilah, maka persamaan dari motode Altman Z-Score adalah : 


$$
Z=1,2 X_{1}+1,4 X_{2}+3,3 X_{3}+0,6 X_{4}+1,0 X_{5}
$$

Dalam metode Altman Z-Score mempunyai angka-angka cut off nilai Z-Score yang menunjukkan akankah perusahaan tersebut menghadapi kesulitan keuangan maupun tidak di masa depan dengan dibagi menjadi 3 golongan yakni jika nilai Z-Score > 2,99 maka termasuk perusahaan yang tidak mengalami kesulitan keuangan sehingga dapat digolongkan dalam perusahaan tidak bangkrut, nilai 1,81<Z-Score $<2,99$ maka perusahaan tersebut dapat digolongan sebagai perusahaan yang rawan bangkrut atau terdapat pada kondisi grey area dimana tidak dapat ditentukan apakah perusahaan tidak bangkrut atau bangkrut, nilai Z-Score < 1,81 maka dapat digolongkan perusahaan yang mengalami kesulitan keuangan atau bangkrut (Hanafi, 2014: 657).

Metode Zmijewski mempunyai fungsi untuk menganalisis rasio yang digunakan untuk menghitung kinerja keuangan, likuiditas, serta solvabilitas suatu perusahaan. Maka dapat diperoleh persamaan motode Zmijewski sebagai berikut :

$$
X=-4,3-4,5 X_{1}+5,7 X_{2}-0,004 X_{3}
$$

Dalam Dalam analisis Zmijewski menggunakan nilai cut off $\mathrm{X}=0$, sehingga perusahaan yang memiliki $X>0$ atau positif (+) dapat digolongan sebagai perusahaan mengalami kebangkrutan, serta apabila $X>0$ atau negatif (-) dapat digolongkan perusahaan yang sehat.

\section{HASIL DAN PEMBAHASAN}

Tabel 1

Data Variabel Pembentuk Nilai Prediksi Kebangkrutan Model Altman Z-Score PT Bakrie Telecom Tbk

Tahun 2015-2017

\begin{tabular}{|l|r|r|r|}
\hline \multicolumn{1}{|c|}{ Komponen } & \multicolumn{1}{|c|}{2015} & \multicolumn{1}{|c|}{2016} & \multicolumn{1}{l|}{2017} \\
\hline Aset Lancar & 64.014 & 43.516 & 718.022 \\
\hline Total Liabilitas/Hutang lancar & 7.649 .163 & 8.191 .029 & 2.649 .163 \\
\hline Total Assets & 2.411 .596 & 1.569 .775 & 2.41 .596 \\
\hline Retaining Earnings & 18.673 .601 & 20.065 .744 & 2.562 .226 \\
\hline Earning Before Interest and Taxes & 5.161 & 9.650 & 14.155 .424 \\
\hline Market Value of Equity & 12.513 .155 & 13.897 .548 & 14.873 .446 \\
\hline Book Value of Total Debt & 14.924 .751 & 15.467 .323 & 7.871 \\
\hline Sales & 509.596 & 119.365 & \\
\hline
\end{tabular}

Sumber : $\underline{\text { www.idx.co.id }}$ 
Tabel 2

Data perhitungan prediksi kebangkrutan model Altman Z-Score

\begin{tabular}{|c|c|c|c|c|c|c|c|c|}
\hline Tahun & Perusahaan & $\begin{array}{c}\text { WCTA } \\
\left(\mathrm{X}_{1}\right)\end{array}$ & $\begin{array}{c}\text { RETA } \\
\left(\mathrm{X}_{2}\right)\end{array}$ & $\begin{array}{c}\text { EBITTA } \\
\left(\mathrm{X}_{3}\right)\end{array}$ & $\begin{array}{c}\text { MVEBVD } \\
\left(\mathrm{X}_{4}\right)\end{array}$ & $\begin{array}{c}\text { SATA } \\
\left(\mathrm{X}_{5}\right)\end{array}$ & Z-Score & Kategori \\
\hline 2015 & BTEL & 3,145 & 7,743 & 0,002 & 0,838 & 0,211 & 15,334 & Sehat \\
\hline 2016 & BTEL & 5,190 & $\begin{array}{c}12,78 \\
2\end{array}$ & 0,006 & 0,898 & 0,760 & 25,395 & Sehat \\
\hline 2017 & BTEL & 12,434 & $\begin{array}{c}30,03 \\
0\end{array}$ & 0,013 & 0,951 & 0,010 & 57,586 & Sehat \\
\hline
\end{tabular}

Perhitungan model Altman Z-Score terhadap PT Bakrie Telecom Tbk pada tahun 2015 sampai dengan 2017 dinyatakan dalam kondisi sehat atau non distress. Hal ini dibuktikan dengan nilai ZScore berada di atas 2,99 yakni tahun 2013 dengan nilai sebesar15,334, tahun 2016 dengan nilai sebesar 25,395, serta tahun 2017 dengan nilai sebesar 57,586.

Tabel 3

Data Variabel Pembentuk Nilai Prediksi Kebangkrutan Model Zmijewski PT Bakrie Telecom Tbk

Tahun 2015-2017

\begin{tabular}{|l|r|r|r|}
\hline \multicolumn{1}{|c|}{ Komponen } & \multicolumn{1}{|c|}{2015} & \multicolumn{1}{c|}{2016} & \multicolumn{1}{c|}{2017} \\
\hline Net Income & 8.506 .407 & 1.330 .333 & 1.605 .235 \\
\hline Total Assets & 2.411 .596 & 1.569 .775 & 718.022 \\
\hline Total Liabilities & 14.924 .751 & 15.467 .323 & 14.873 .446 \\
\hline Current Assets & 64.014 & 43.516 & 5.266 \\
\hline Current Liabilities & 7.649 .163 & 8.191 .029 & 8.933 .611 \\
\hline
\end{tabular}

Sumber : www.idx.co.id

Tabel 4

Data perhitungan prediksi kebangkrutan model Zmijewski

Tahun 2015-2017

\begin{tabular}{|c|c|c|c|c|c|c|}
\hline Tahun & Perusahaan & $\begin{array}{c}\text { NITA } \\
\left(\mathrm{X}_{1}\right)\end{array}$ & $\begin{array}{c}\text { TLTA } \\
\left(\mathrm{X}_{2}\right)\end{array}$ & $\begin{array}{c}\text { CACL } \\
\left(\mathrm{X}_{3}\right)\end{array}$ & X-Score & Kategori \\
\hline 2015 & BTEL & 3,53 & 6,19 & 0,0084 & $-55,46$ & Sehat \\
\hline 2016 & BTEL & 0,85 & 9,85 & 0,0053 & 48,01 & Bangkrut \\
\hline 2017 & BTEL & 2,24 & 20,71 & 0,00059 & 103,67 & Bangkrut \\
\hline
\end{tabular}

Perhitungan model Zmijewski terhadap PT Bakrie Telecom Tbk pada tahun 2015 dinyatakan sehat atau non distress, hal ini dibuktikan dengan nilai $X$-Score lebih keci dari 0 atau negatif (-) yaitu dengan nilai sebesar -55,46. Sedangkan pada tahun 2016 sampai dengan tahun 2017 PT Bakrie Telecom Tbk dinyatakan bangkrut atau distress, ha ini ditunjukkan dengan nilai $X$-Score lebih besar 
dari 0 atau positif (+) yaitu pada tahun 2016 dengan nilai sebesar 48,01 dan pada tahun 2017 dengan nilai sebesar 103,67.

\section{KESIMPULAN DAN SARAN \\ Kesimpulan}

Menurut penelitian yang telah dilaksanakan kepada PT. Bakrie Telecom Tbk yang tercantum dalam BEI (Bursa Efek Indonesia) di tahun 2015-2017 dengan memakai analisis kebangkrutan dengan metode Altman Z-Score dan Zmijewski, maka hasilnya bisa diberikan kesimpulan sebagai berikut :

a. Metode Altman Z-Score

\begin{tabular}{|c|c|c|c|}
\hline Tahun & Nilai Z-Score & Nilai Cut Off & Klasifikasi \\
\hline 2015 & 15,334 & $>2,99$ & Tidak bangkrut \\
\hline 2016 & 25,395 & $>2,99$ & Tidak bangkrut \\
\hline 2017 & 57,586 & $>2,99$ & Tidak bangkrut \\
\hline
\end{tabular}

Berdasarkan perhitungan prediksi kebangkrutan dengan menggunakan metode Altman ZScore terhadap PT Bakrie Telecom Tbk pada tahun 2015-2017, membuktikan bahwa kondisi perusahaan dari tahun 2015-2017 dalam kondisi tidak bangkrut.

b. Metode Zmijewski

\begin{tabular}{|c|c|c|l|}
\hline Tahun & Nilai $X$-Score & Nilai Cut Off & Klasifikasi \\
\hline 2015 & $-55,46$ & $<0$ atau negativ $(-)$ & Tidak bangkrut \\
\hline 2016 & 48,01 & $>0$ atau postif $(+)$ & Bangkrut \\
\hline 2017 & 103,67 & $>0$ atau positif $(+)$ & Bangkrut \\
\hline
\end{tabular}

Berdasarkan perhitungan prediksi kebangkrutan dengan menggunakan metode Zmijewski terhadap PT Bakrie Telecom Tbk pada tahun 2015-2017, membuktikan bahwa kondisi perusahaan di tahun 2015 dalam kondisi tidak bangkrut, sedangkan di tahun 2016 dan tahun 2017 perusahaan dalam kondisi bangkrut.

c. Dari kedua metode tersebut menghasilkan perhitungan dan prediksi yang tidak sama dikarenakan setiap metode memiliki variabel hitung yang berbeda dan memiliki biaya yang dikeluarkan oleh perusahaan pada setiap tahunnya juga berbeda. Selain itu terdapat pula yang membedakan antara kedua metode tersebut yaitu dalam metode Altman Z-Score lebih mengarah pada laba sedangkan metode Zmijewski lebih mengarah pada hutang.

\section{Saran}

Berdasarkan penelitian yang telah dilakukan peneliti, maka peneliti dapat mengajukan saran dalam penelitian ini sebagai berikut :

a. Perusahaan diharapkan melakukan inovasi, pengembangan, serta perbaikan organisasi agar mampu bersaing dengan kompetitornya.

b. Perusahaan diharapkan agar dapat melindungi serta menambah kestabilan modal kerja perusahaan, sebab modal kerja adalah hal terpenting dalam memutuskan tingkat likuiditas perusahaan. Dalam hal ini dapat menggunakan beberapa cara yaitu melakukan penjualan dari aset tetap, investasi jangka panjang, serta aktiva lancar lainnya yang suda tidak lagi dibutuhkan bagi perusahaan. 
c. Perusahaan diharapkan mampu mengunakan aset secara efektif dan efisien sebagai menaikkan pemasaran serta memperoleh keuntungan yang semakin besar ketika memelihara profitabilitas perusahaan.

d. Pada penelitian selanjutnya diharapkan mampu menganalisis prediksi tingkat kebangkrutan pada perusahaan dengan periode pengamatan yang lebih lama serta menggunakan jenis metode prediksi kebangkrutan lain agar mendapatkan hasil penelitian yang lebih efektif dan maksimal.

\section{DAFTAR PUSTAKA}

Boedi Soelistijono dan Tiara Devi. 2013. Analisis Prediksi Kebangkrutan Perusahaan Telekomunikasi Yang Terdaftar Di Bursa Efek Indonesia Dengan Model Altman Revisi. Jurnal Manajemen dan Akutansi. Vol. 14, No.1, April 2014.

Effendi Ria. 2018. Analisis Prediksi Kebangkrutan Dengan Metode Altman, Springate, Zmijewski, Foster, Dan Grover Pada Emiten Jasa Transportasi. Jurnal Parsimonia. Vol. 4, No. 3, Januari 2018.

Hanafi, Mamduh M. 2014: 657. Manajemen Keuangan. Jakarta: PT Raja Grafindo Persada.

Harahap, Sofyan Syafitri. 2013. Analisis Kritis Atas Laporan Keuangan. Cetakan Kesebelas. Jakarta: Rajawali Pers.

Kadim Abdul dan Sunardi Nardi. 2018. Analisis Altman Z-Score Untuk Memprediksi Kebangkrutan Pada Bank Pemerintah (Bumn) Di Indonesia Tahun 2012-2016. Jurnal Sekuritas. Vol.1, No.3 , Maret 2018.

Siregar Wulan Ibrahim, Maihetti Selvi, dan Supriyanto. 2016. Prediksi Finanncial Distress Pada Pt. Jaya Agra Wattie Tbk Dengan Menggunakan Model Altman Z-Score. Jurnal Bisnis Administrasi. Vol 05, No. 02, 2016.

Sugiyono. 2011: 8. Metode Penelitian Kuantitatif, Kualitatif dan R\&D. Bandung: Afabeta.

Sugiyono. 2011: 29. Metode Penelitian Kuantitatif, Kualitatif dan R\&D. Bandung: Afabeta.

Tambunan Rafles W, Dwiatmanto, Endang N.P. 2015. Analisis Prediksi Kebangkrutan Perusahaan Dengan Menggunakan Metode Altman (Z-Score) (Studi Pada Subsektor Rokok Yang Listing Dan Perusahaan Delisting Di Bursa Efek Indonesia Tahun 2009 - 2013). Jurnal Administrasi Bisnis (JAB). Vol. 2 No. 1 Februari 2015. 